\title{
LEGAL INSTITUTIONS AND INFORMAL NETWORKS
}

\author{
Ethan Bueno de Mesquita and Matthew Stephenson
}

\begin{abstract}
The relationship between third-party contract enforcement and informal networks raises important sociological, political, and economic questions. When economic activity is embedded in social structures, what are the implications of third-party contract enforcement for the scope and nature of economic relations? What determines whether individuals rely on formal legal institutions or informal networks to sustain trade relationships? Do legal institutions erode informal networks? We develop a model in which a trade-off exists between size and sustainability of networks. By adding the possibility of feebased, enforceable contracts, we provide a theoretical explanation for the coexistence of legal contract enforcement and an informal economy. We find that legal enforcement has little effect on networks until law becomes sufficiently inexpensive, at which point small decreases in the cost of law have dramatic effects on network size and the frequency of use of the legal system.
\end{abstract}

KEY WORDS • informal economy $\bullet$ informal networks $\bullet$ legal institutions $\bullet$ social norms $\bullet$ transaction costs

\section{Introduction}

Third-party contract enforcement is thought to be one of the essential public goods provided by governments. Nonetheless, in societies without welldeveloped governmental institutions for the enforcement of contracts, cooperative economic interactions still take place; informal networks make such cooperation possible (Granovetter, 1973; Moore, 1978; Landa, 1981; Weiss, 1987; Benson, 1990; Ellickson, 1991; Bernstein, 1992; Greif, 1993; Winn, 1994). Examples of such networks include the club-like relationship

We are particularly indebted to Bob Bates, John Ohnesorge, Ken Shepsle, and Anne-Marie Slaughter, for whose graduate seminars this paper was originally written. We have also benefited from the comments of Scott Ashworth, Chris Avery, Bruce Bueno de Mesquita, Charles Cohen, Eric Dickson, Amanda Friedenberg, Catherine Hafer, Andrew Martin, Matt Price, Jas Sekhon, David Andrew Singer, Alastair Smith, Jim Snyder, Christine Taylor, and Leeat Yariv. 
among Chinese rubber merchants in Malaysia (Landa, 1981), the informal economy of Peruvian street vendors (De Soto, 1989), and the reputationbased management of agency relationships established by medieval Jewish merchants in the Mediterranean (Greif, 1993). Moreover, there is evidence that such networks persist even with the development of sophisticated legal enforcement (Macaulay, 1963; Landa, 1981; De Soto, 1989; Ellickson, 1991; Fafchamps, 1996; DiMaggio and Louch, 1998) and within highly industrialized societies (Portes and Sassen-Koob, 1987). Indeed, it has been argued that such networks, rather than formal institutions, are the chief building blocks of sustainable economic relationships, even in modern economies (Granovetter, 1973). Wisconsin businessmen, California ranchers, and Taiwanese entrepreneurs have all been observed to rely more on personal relationships and informal agreements than on formal legal enforcement mechanisms (Macaulay, 1963; Ellickson, 1991; Winn, 1994).

The relationship between formal, legal contract enforcement and informal networks raises a number of important question. First, if the government fails to provide adequate third-party contract enforcement, what are the implications for the scope and nature of economic interactions? Second, what determines whether individuals will choose to rely on formal legal institutions or their informal social networks, when both are available? This question is particularly important for governments attempting to build an effective legal infrastructure. Third, to what extent does the introduction of governmental contract enforcement erode the social networks that sustain the informal economy? This is a matter of concern inasmuch as governments value both the positive effects of social ties maintained through informal networks and the greater societal cohesion achieved by replacing narrow social networks with a more formalized, integrated economy.

These issues lie at the nexus of several disciplines within the social sciences. Sociologists have a long tradition of examining how social structures other than the market - such as informal trade networks - affect economic interactions (Polanyi, 1957; Granovetter, 1985; Powell and Smith-Doerr, 1994; Uzzi, 1999; Uzzi and Lancaster, 2004). Further, the question of how government policies and legal institutions impact economic outcomes and social structures are of interest to sociologists, political scientists, and economists alike (Skocpol, 1985; Shapiro, 1987; North, 1990; Platteau, 1994; Edelman and Suchman, 1997).

In order to address these issues, we develop a model of informal networks in the absence of legal contract enforcement. We then introduce the possibility of legal contracts and analyze the effects on these networks. In our model, cooperation in informal networks is sustained through repeated play. The punishment-based enforcement mechanism limits the number of trading partners with whom cooperation can be sustained. As the number of potential trading partners grows, the probability of interacting repeatedly 
with any one individual decreases. However, as long as the network does not grow so large that cooperation is unsustainable, utility-maximizing individuals want to be in as large a network as possible. Expected gains from trade in such networks increase as the network size grows because individuals are likely to find more profitable trading partners among a larger group of potential partners.

By modelling the trade-off between size and sustainability of cooperation, we identify the optimal size of informal trading networks as a function of other parameters. We extend our model by introducing the possibility of costly legal contract enforcement. Players choose between a costly, formal contract that allows them to cooperate with their most-preferred trading partner in the entire population and informal trade with their most-preferred partner within their informal network. Using computational methods, we find that informal trade networks often persist when formal legal enforcement becomes possible. Further, in many cases where the possibility of legal enforcement exists, it will neither be used nor have a significant effect on the size of informal trade networks unless it is sufficiently inexpensive. Finally, we find that economic agents' expected utility is not monotonic in the cost of law so that, in some circumstance, agents will not want contract enforcement to become as inexpensive as possible. Thus, we provide a theoretical explanation for the continuation of informal networks even when third-party contract enforcement is possible and demonstrate the relationship between the cost of legal enforcement, the size of informal networks, and the relative importance of the formal and informal economies.

\section{Literature Review and Puzzles}

Sociologists have paid particular attention to the use of informal networks to alleviate the uncertainty inherent in trading with strangers (DiMaggio and Louch, 1998; Mizruchi and Brewster Stearns, 2001). The more risky a particular interaction is, the more likely individuals are to trade in a network where trust has developed. Our analysis hinges on this insight, in the sense that people in our model trade within their networks precisely because members of the larger economic world cannot be trusted to deliver on promises. We then examine how the existence of formal institutions for the enforcement of contracts attenuates the riskiness of out-of-network interactions and, thereby, affects the size of informal networks.

The explanation of cooperative networks that is most familiar to economists, and which is closely related to the idea of networks as a response to uncertainty, is reputation and repeated play. If self-interested players expect to interact many times, they can maintain cooperation through punishment strategies, assuming they care enough about the future. 
Although punishing past defections can sustain cooperation, it limits the size of informal groups. As groups become larger, the likelihood of interacting with any particular person in a given turn decreases, making cooperation more difficult to sustain. However, individuals benefit from being in larger groups where they are more likely to find profitable trading partners. Thus, there is a trade-off between sustaining cooperation and increasing diversity of trading partners.

Information-sharing institutions are one possible solution to the problem of limited group size. If information can be credibly transmitted, then cooperation can be sustained in larger groups because players can punish not just players who have cheated them, but players who have cheated anyone (Milgrom et al., 1990; Bernstein, 1992; Greif, 1993). However, efficient information sharing becomes more difficult to sustain effectively as groups grow. Hence, it is often argued that reputational enforcement mechanisms are inadequate to sustain cooperation in large, complex societies and thus become obsolete when formal legal enforcement of contracts becomes possible (North, 1990; Platteau, 1994).

Moreover, it has been theorized that legal enforcement eliminates the need for informal trading networks. Legally binding contracts ensure that individuals can enter into mutually cooperative relationships with their most profitable trading partner, even if they never expect to interact again. Therefore, according to this theory, legal institutions will replace informal trade networks (Lee, 1993; Kranton and Swamy, 1999). However, empirical evidence indicates that economic activity continues to be embedded in such networks even in societies with highly developed legal institutions (Macaulay, 1963; Ellickson, 1991; DiMaggio and Louch, 1998). And, such informal mechanisms are in many cases the norm, persisting long after legal enforcement becomes available (Granovetter, 1973; Landa, 1981; De Soto, 1989; Fafchamps, 1996). Indeed, in many such cases, the formal legal institutions are rarely used at all. This has led other scholars to conclude that the law is of little relevance in these societies (Ellickson, 1991; Winn, 1994).

Both characterizations miss fundamental aspects of the choice between legal and reputational enforcement mechanisms. The former relies on the assumption that legal enforcement is costless, and the latter overlooks the complex interaction between the legal system and informal networks. Our model, in which individuals can trade in both the informal and formal economies, provides a more nuanced perspective on this issue.

In order to focus our discussion on the primary questions of interest - the effect of law on networks - we necessarily abstract away from some of the richness and nuance that has been developed in the literature on informal networks. For instance, while cultural and ethnic theorists have argued that one of the keys to sustainability of informal networks is that members of a particular group share similarities that foster trust by making internal 
monitoring easier (Colson, 1974; Landa, 1981; Bernstein, 1992; Greif, 1993; Fearon and Laitin, 1996), we do not model these cultural effects. Nor does our model directly incorporate the common argument that cooperative networks are sustained through social norms that change people's preferences through an evolutionary or socialization process such that individuals prefer cooperation, even when they could shirk without being caught (Ellickson, 1991; Cooter, 1996). And, as noted above, we do not include information-sharing institutions.

We adopt these simplifications not because we dispute the importance of ethnic or cultural subgroups, norm-based preferences for selfless cooperation, or information sharing, but rather because our stylized model allows us to explore the particular question of interest in this work. Clearly, ethnic and cultural ties, social norms that favor cooperation, and information sharing all strengthen the linkages that sustain informal networks. By abstracting away from precisely those elements of networks that make cooperation most likely, we are considering the most difficult case. If informal trade networks persist in our model, without the sustaining effects of ethnic and cultural ties, social norms, or information sharing, they will be all the more robust in a richer model that includes these reinforcing elements. And, indeed, in our model, in which agents are homogenous, narrowly selfinterested, and not privy to information about interactions that they do not personally observe, cooperative trade networks still emerge in equilibrium. Further, our model provides a theoretical explanation for why economic interactions continue to be embedded in informal networks despite the existence of legal enforcement. We demonstrate that formal legal enforcement will rarely be used in societies with informal networks when such enforcement is expensive. This, however, does not imply that legal enforcement of contracts will always remain irrelevant in such societies. A sufficient decrease in the cost of law could lead to a dramatic increase in use of formal legal institutions.

Although we abstract away from some issues that sociologists identify as important elements of informal networks, such as trust, our model also yields some results that look similar to sociological findings. For instance, Uzzi $(1996,1997)$ argues that there is an optimal level of embeddedness for economic agents. On the one hand, if they are not sufficiently embedded, agents forgo the benefits of cooperative network interactions. On the other hand, an agent that is too socially embedded will fail to capitalize on economic and informational gains associated with interactions with the larger world. Our model is precisely in this spirit. When it is possible to interact with the larger world (i.e. when there is third-party enforcement) our agents choose a level of embeddedness (how often they interact in their network versus with the larger world) in order to maximize their expected utility. They recognize the trade-off that Uzzi identifies; they want to sustain their 
informal networks but are unwilling to do so at the expense of not benefiting from the opportunities associated with the larger world. The fact that our model of networks sustained through repeated play and threatened punishments so closely parallels a model of networks grounded in a trust-based argument leads us to suspect that the way these two types of mechanisms operate may be very similar. If this is so, then our model need not be interpreted as a narrowly punishment-based story that ignores the importance of trust. Rather, it may be a more general account in which our mechanism and trust-based mechanisms are closely related. We return to this issue in the conclusion.

\section{The Model}

Consider an individual, $i$, who is a member of a society, $\mathbf{W}$, of size $W$ and of an informal trading group $\mathbf{N} \subset \mathbf{W}$ which is a subset of that society and of size $n+1, n \in \mathbb{N}$.

In each round one player is selected from $\mathbf{W}$ by nature and labeled the selector, which means that he or she has the opportunity to choose a trading partner and engage in trade. The player he or she chooses to trade with is the selectee. A player, $i$, has probability $1 / W \equiv \alpha$ of being the selector. The selector, $i$, has $n_{i}$ potential trading partners. Let $N_{i}=\{1, \ldots, n+1\}$ be the set of all members of player $i$ 's trading group and $N_{-i}$ be the same set, excluding player $i$. If $j \in N_{i}$ we assume $i \in N_{j}$. But we do not assume that if $j \in N_{i}$ and $k \in N_{i}$ then $j \in N_{k}$.

At the beginning of a round, trades between each dyad of players are assigned a value. A player observes the total value of a trade between him or herself and each other individual. The value of the trade between players $i$ and $j$, in period $t$, is given by the random variable $V_{t}(i, j): \mathbf{W} \times \mathbf{W} \rightarrow[0,2]$. We assume that $V_{t}(i, j)$ is distributed uniformly on the interval [0,2]. Each trader receives half the value of a trade. Thus the value to player $i$ of a deal with player $j$ in round $t$ is $V_{i}^{t}(j)=V_{j}^{t}(i)=V_{t}(i, j) / 2 \sim U[0,1]$. Each $V_{t}(i, j)$ is independent and identically distributed. That is, the value of the deal between players $i$ and $j$ is uncorrelated with either of their individual values to any other player $k$, and is uncorrelated with the value of a deal between them in previous rounds.

In each round, the selector chooses his or her best trading partner in their network and they play a Prisoner's Dilemma. If they both cooperate, they split the full value of the trade. If one defects, the defector gets their half of the deal plus a benefit $b>0$. The player who is defected against receives a negative payoff of $-r b$, with $r>(1-b) / b$. If both defect, both players receive a payoff of 0 . The stage game is represented in Figure 1, where player $i$ 's strategies are the rows and player $j$ 's are the columns. 


\begin{tabular}{c|c|c|}
\multicolumn{1}{c}{} & \multicolumn{1}{c}{ Cooperate } & \multicolumn{1}{c}{ Defect } \\
\cline { 2 - 3 } Cooperate & $V_{i}^{t}(j), V_{j}^{t}(i)$ & $-r b, V_{j}^{t}(i)+b$ \\
\cline { 2 - 3 } Defect & $V_{i}^{t}(j)+b,-r b$ & 0,0 \\
\cline { 2 - 3 } & &
\end{tabular}

Figure 1. The Stage Game

This set-up is a departure from much of the literature on networks, which frequently employs social-matching games (Milgrom et al., 1990; Fearon and Laitin, 1996). ${ }^{1} \mathrm{We}$, instead, allow each player to choose his or her best trading partner, which allows players to benefit economically from membership in a larger network: the greater the number of potential trading partners, the more likely a player is to find a highly profitable trade. In particular, in each round a player's expected valuation of his or her best trade is the $n^{\text {th }}$ order statistic of $n$-draws from a uniform distribution between 0 and $1 .^{2}$ In a uniform distribution, the expected value of the $n^{\text {th }}$ order statistic is given by the formula $n / n+1$, which is increasing in the size of the network.

The game is played in infinite repetition. Players discount the future with a common, constant discount rate $\delta \in(0,1)$. We assume that players costlessly remember all of their own previous interactions but do not observe others' interactions.

To summarize, the sequence of events in a single round of play is as follows. First, a selector is chosen at random and he or she observes the value of each potential match. Second, the selector chooses the partner with whom the value of trading is maximal. Finally, this selector and the selectee play a Prisoner's Dilemma.

\section{Analysis and Results}

In this section, we solve the model for an equilibrium of interest and develop an extension in which we add the possibility of legally enforceable contracts. We focus on the strategy profile in which each player plays the following strategy: player $i$ cooperates with player $j$ if and only if player $j$ has never

1. An interesting approach that uses the Prisoner's Dilemma to explore the emergence of cooperation without assuming a social matching game is Macy and Skvoretz (1998). For a discussion of the use of the Prisoner's Dilemma as a model of social interactions see Lomborg (1996).

2. The $n^{\text {th }}$ order statistic of $\mathrm{n}$-draws is the single highest draw. 
defected against them and he or she has never defected against player $j$, in which case he or she defects against player $j$ forever. ${ }^{3}$ We begin by analyzing the optimal size of an informal trade network. We then include the possibility of costly, third-party contract enforcement, and explore, computationally, how informal and formal enforcement mechanisms interact.

\subsection{Optimal Network Size}

The first question we consider is the maximum sustainable size of an informal network in which all players cooperate with one another.

Players prefer to be in as large a network as possible, as long as cooperation is sustained. Given cooperation, the expected value of each interaction in an informal network is $n / n+1$, which is strictly increasing in $n$. As an informal trading network grows, cooperation becomes more difficult to sustain through punishment mechanisms because as $n$ increases the probability that a player will interact with any particular member of his or her network in a given round, $2 \alpha / n$, decreases. Players maximize their utility by being in a network that is as large as possible while sustaining cooperation. We label this optimal number of informal partners as $n^{*}$.

In order to determine $n^{*}$ we find the conditions under which a player, $i$, will cooperate. We adopt the following notation. Let $C_{i}$ denote the strategy for player $i$ in which he or she always plays cooperate against another player if neither of them has ever defected against the other and otherwise always defects against that player. Let $D C_{i}$ denote the same strategy with a oneshot deviation to defection. We write a general strategy profile as $\left(X, Y_{-i}\right)$, where $X$ is player $i$ 's strategy and $Y_{-i}$ is all other players' strategy. Player $i$ 's discounted expected utility from such a strategy profile is given by $E U_{i}\left(X, Y_{-i}\right)$. Thus, the expected utility to $i$, in a round in which he or she is the selector, of adopting a cooperative strategy given that all others cooperate is

$$
E U_{i}\left(C, C_{-i}\right)=\left(1+\frac{2 \alpha \delta}{1-\delta}\right) \frac{n}{n+1} .
$$

If player $i$ were to defect in one round, assuming that everyone else cooperates he or she would get an expected payoff of $(n /(n+1))+b$. As a result of this defection, in each subsequent round where he or she is the selector, he or she can only choose from $n-1$ rather than $n$ possible partners. Further, the probability that someone else in his or her network will be selected and then

3. We focus on this strategy because it is the simplest version of the type of punishment scheme that we are interested in. 
choose to trade with him or her decreases from $\alpha$ to $\alpha(n-1) / n$. Thus, we can write $i$ 's expected utility from a one-shot deviation, if all others are cooperating, as

$$
E U_{i}\left(D C, C_{-i}\right)=\frac{n}{n+1}+b+\left(\frac{\alpha \delta}{1-\delta}\right)\left(\frac{n-1}{n}+\frac{n-1}{n+1}\right) .
$$

If $E U_{i}\left(C, C_{-i}\right) \geq E U_{i}\left(D C, C_{-i}\right)$ then all $i \in N$ have an incentive to cooperate. If, however $E U_{i}\left(C, C_{-i}\right)<E U_{i}\left(D C, C_{-i}\right)$, then player $i$ prefers to defect if their partner is expected to cooperate. If the partner is expected to defect, $i$ will always defect as well. In any trading pair $(i, j)$ if $i$ and/or $j$ defect, they will never cooperate with one another again. Player $i$ suffers this same loss of a trading partner for all future rounds whether they defect or not. But in the current round, if he or she defects they receive a payoff of 0 and if he or she cooperates they receive a payoff of $-r b<0$. Hence, $E U_{i}\left(C, D_{-i}\right)<E U_{i}\left(D C, D_{-i}\right)$ for all $i$. This implies that all players will cooperate if and only if

$$
E U_{i}\left(D C, C_{-i}\right)-E U_{i}\left(C, C_{-i}\right)=\frac{n(1-2 \alpha)}{n+1}+b-\frac{\alpha \delta}{n(1-\delta)} \leq 0
$$

If the above inequality does not hold player $i$ defects. Therefore, $n^{*}$ (given $\delta, b$, and $\alpha$ ) is the largest integer for which equation (3) holds. Because all players have identical utility functions, all players will have the same $n^{*}$. We can solve for this $n^{*}$ explicitly by rearranging terms in equation (3):

$$
n^{*}=\left\lfloor\frac{\alpha \delta}{b(1-\delta)}\right\rfloor
$$

Proposition 1: Given values of $\delta, b$, and $\alpha$ a unique optimal network size, $n^{*}+1$, exists. Moreover, the optimal network size is weakly increasing in $\delta$ and weakly decreasing in $b$.

Proof. The right-hand side of equation 4 is strictly positive. Thus, an optimal network size greater than or equal to 0 exists and is clearly unique. The comparative statics follow directly.

Cooperative interaction is possible through informal networks, in the absence of third-party enforcement, generalized norms of reciprocity, information-sharing institutions, or differentiation between agents (such as ethnic or cultural subgroups). The size of an informal trade network is bounded above by $n^{*}$. As $n$ increases, the expected payoff from cooperation, $n / n+1$, increases but the probability that two players will meet in any given round, $2 \alpha / n$, decreases. This creates a trade-off: as $n$ increases, cooperation is more profitable but harder to sustain. Further, as $\delta$ increases, 
so that players care more about the future, the size of the maximum sustainable cooperative network increases. Players who care more about the future can more easily commit to cooperating to avoid long-term punishment. As the benefit from defection, $b$, increases, cooperation becomes more difficult to sustain and group size decreases.

This can be made even more concrete by considering a numerical example. Consider a society characterized by the following parameter values: $\delta=0.85, b=0.0001, W=1000 .{ }^{4}$ In this scenario, the optimal network size is $n^{*}+1=\lfloor\alpha \delta / b(1-\delta)\rfloor+1=\lfloor .001 * 0.85 / .0001 * 0.15\rfloor+1=57$. Plugging in to equation 1 , we can find the payoff to cooperation in the optimal network:

$$
E U_{i}\left(C, C_{-i} \mid b=0.0001, \delta=0.85, W=1000, n=56\right) \approx 0.993591 .
$$

Similarly, plugging in to equation 2, we can find the payoff to defection in the optimal network:

$$
E U_{i}\left(D C, C_{-i} \mid b=0.0001, \delta=0.85, W=1000, n=56\right) \approx 0.993589 .
$$

Thus, the players will cooperate. A slightly larger network, however, is not sustainable. Indeed, if the network is increased in size by just one person, then the payoffs are

$$
E U_{i}\left(C, C_{-i} \mid b=0.0001, \delta=0.85, W=1000, n=57\right) \approx 0.9938970
$$

and

$$
E U_{i}\left(D C, C_{-i} \mid b=0.0001, \delta=0.85, W=1000, n=57\right) \approx 0.9938971
$$

leading to defection.

\subsection{The Possibility of Third-party Contract Enforcement}

In the original formulation of the model, players could only engage in exchange with members of their informal trade network. In this section we analyze how the possibility of third-party enforceable contracts affects the equilibrium we found in our earlier analysis.

\footnotetext{
4. Notice that the payoff from defection $(b)$ is taken to be small relative to the value of the trade. This is because the probability of playing in any given round is very small. Players only expect to play in 1 out of every 500 rounds. Thus, the actual per-round expected payoff to a player is on the order of $1 / 500$. We select $b$ to be of the same order of magnitude.
} 
In each round, the selector has a choice between informal trade within his or her network or going outside such network to make a formal contract. This is a departure from earlier approaches to modeling interactions between legal and informal enforcement, which have tended to assume that players are either part of the informal, reputation-based economy or the formal, contract-based economy (Landa, 1981; Cooter and Landa, 1984; Kali, 1999). In our model, this choice is endogenous, and made each round.

A player, $i$, makes the decision either to write a formal contract or trade within his or her network after observing $V_{-i}^{t}(j)$ for all $j \in \mathbf{W}$. If player $i$ chooses to write a formal contract, he or she finds a trading partner outside of his or her network, whose expected value to he or she is $(W-n-1) /$ $(W-n) .{ }^{5}$ However, contract enforcement carries a fixed cost $c \in[0,1]$. Once a contract is written, we assume perfect enforcement. Because in equilibrium cooperation is always sustained in informal trade networks, players never write formal contracts with members of their own network. However, they can write formal contracts with ex-members of their network against whom they have defected, or who have defected against them, in the past.

Note that this is not a change to the information structure of the game. As in the model of networks in the absence of a legal option, players can observe the value of trade with every other player. However, in that earlier version, information about players outside of one's informal network was not useful because cooperation with them was not sustainable.

Play proceeds as before, with the addition of the decision over whether or not to write a formal contract. Assume that $n \leq n^{*}$, so that cooperation is sustained in the informal networks. In round $t$, where player $i$ has been selected to trade, he or she chooses to write a formal contract if and only if

$$
\max _{j \in \mathbf{W}} V_{i}^{t}(j)-c>\max _{j \in N_{-i}} V_{i}^{t}(j),
$$

otherwise $i$ trades with his or her best trading partner in their network, and they play the same stage game as in the basic model.

As before, we must identify the maximum value of $n$ for which cooperation is sustainable in informal trade networks. By the same logic developed earlier, cooperation will be the equilibrium strategy if and only if $E U_{i}\left(C, C_{-i}\right) \geq E U_{i}\left(D C, C_{-i}\right)$. We begin our analysis of the expected utility functions in a round in which the selector, $i$, will choose to interact within her network. ${ }^{6}$ This first round payoff for defecting versus cooperating will only differ by $b$, the benefit from defecting. We refer to this first-round payoff (excluding the payoff from defecting) as $R$.

5. Note that when $W$ is large this term is very close to 1 .

6. If we began the analysis in a round in which player $i$ writes a formal contract, then defection is not an option. As we are comparing the expected utility from defecting versus cooperating, the only case that is of interest is one in which player $i$ has the option to do either. 
The expected utility from always cooperating, given that others will cooperate, is equal to the first period payoff of $R$ plus the expected value of mutual cooperation for all subsequent rounds, given that in some of those rounds in which he or she is the selector, player $i$ may choose to use the law rather than trade in his or her informal network, and that in some of those rounds he or she will be the selectee. We can write the expected utility to player $i$ of cooperating, given that others will cooperate, and given that legal enforcement is possible, as the summation of four terms. We describe each of the four terms below, but the actual derivation is in the appendix.

1. The first term is the probability that player $i$ is the selector, times the probability that he or she can find at least one partner in his or her network with whom a trade is more valuable than writing a formal contract with someone outside this network, times the expected utility to player $i$ of this within-network trade;

2. The second term is the probability that $i$ is the selector, times the probability that there is no one in his or her network with whom he or she would prefer to trade rather than write a formal contract with someone outside this network, times the expected utility of this out-of-network trade;

3. The third term is the probability that someone else in player $i$ 's network is chosen as the selector, times the probability that person chooses to trade within the network, times the probability that $i$ is that player's most valuable informal partner and therefore the selectee, times the expected utility to player $i$ of this within-network trade;

4. The fourth term is the probability that someone not in player $i$ 's newtork is the selector, times the probability that player writes a formal contract outside of his or her network, times the probability that $i$ is that player's best partner in $\mathbf{W}$, times the expected utility to player $i$ of that out-ofnetwork trade. ${ }^{7}$

As shown in the appendix, the expected utility of cooperating is

$$
\begin{aligned}
E U_{i}^{L a w}\left(C, C_{-i}\right)= & R+\frac{2 \alpha \delta}{1-\delta}\left[\left(1-c-\frac{1}{W-n}\right)^{n+1}\right. \\
& +\sum_{m=1}^{n}\left(\begin{array}{c}
n \\
m
\end{array}\right)\left(c+\frac{1}{W-n}\right)^{m}\left(1-c-\frac{1}{W-n}\right)^{n-m} \\
& \left.\times\left(\frac{m+1-c-(1 /(W-n))}{m+1}\right)\right]
\end{aligned}
$$

7. We assume that players treat all networks as if they were the same size as their own when calculating probabilities. 
A similar procedure yields the expected utility from defecting, except that after defecting player $i$ now has a network of size $n$ rather than $n+1$. However, others still have networks of size $n+1$ because all others cooperate. Player $i$ defects in round one, securing an expected payoff of $R+b$ in that round. Then his or her expected utility is the summation of five terms.

1. The first term is the probability that player $i$ is the selector, times the probability that he or she can find at least one partner in his or her network with whom a trade is more valuable than writing a formal contract with someone outside this network, times the expected utility to player $i$ of this within-network trade;

2. The second term is the probability that player $i$ is the selector, times the probability that there is no one in his or her network with whom he or she would prefer to trade rather than write a formal contract with someone outside this network, times the expected utility of this out-of-network trade;

3. The third term is the probability that someone else in player $i$ 's network is chosen as the selector, times the probability that person chooses to trade within the network, times the probability that $i$ is that player's most valuable informal partner and therefore the selectee, times the expected utility to player $i$ of this within-network trade;

4. The fourth term is the probability that someone (other than the player against whom $i$ has already defected) not in $i$ 's group is the selector, times the probability that player writes a formal contract outside of his or her network, times the probability that $i$ is that player's best partner in $\mathbf{W}$, times the expected utility to player $i$ of that out-of-network trade;

5. The fifth term is the probability that the player against whom $i$ defected is the selector, times the probability that player writes a formal contract outside of his or her network, times the probability that $i$ is his or her best trading partner in $\mathbf{W}$, times the expected utility to player $i$ of that trade.

Player $i$ 's expected utility from defecting once, given that all others cooperate, is 


$$
\begin{aligned}
E U_{i}^{L a w}\left(D C, C_{-i}\right) & =R+b+\frac{\alpha \delta}{1-d}\left[\sum_{m=1}^{n-1}\left(\begin{array}{c}
n-1 \\
m
\end{array}\right)\left(c+\frac{1}{W-n+1}\right)^{m}\right. \\
& \times\left(1-c-\frac{1}{W-n+1}\right)^{n-1-m}\left(\frac{m+1-c-(1 /(W-n+1))}{m+1}\right) \\
& +\sum_{m=1}^{n}\left(\begin{array}{c}
n \\
m
\end{array}\right)\left(c+\frac{1}{W-n}\right)^{m}\left(1-c-\frac{1}{W-n}\right)^{n-m} \\
& \times\left(\frac{m+1-c-(1 /(W-n))}{m+1}\right)+\frac{W-n+1}{W-n} \\
& \left.\times\left(1-c-\frac{1}{W-n+1}\right)^{n}+\left(1-c-\frac{1}{W-n}\right)^{n+1}\right]
\end{aligned}
$$

As in the analysis of networks in the absence of law, we can determine whether cooperation is an equilibrium strategy by comparing equation 7 to equation 6. Player $i$ defects if and only if the former is greater than the latter, which is true if

$$
\begin{aligned}
E U_{i}^{L a w}\left(D C, C_{-i}\right)-E U_{i}^{L a w}\left(C, C_{-i}\right) \\
=b+\frac{\alpha \delta}{1-\delta}\left[\sum _ { m = 1 } ^ { n - 1 } \left(\left(\frac{n-1}{m}\right)\left(c+\frac{1}{W-n+1}\right)^{m}\left(1-c-\frac{1}{W-n+1}\right)^{n-1-m}\right.\right. \\
\left.\quad \times\left(\frac{m+1-c-(1 / W-n+1)}{m+1}\right)\right)-\frac{n+1}{n} \sum_{m=1}^{n}\left(\left(\begin{array}{c}
n \\
m
\end{array}\right)\left(c+\frac{1}{W-n}\right)^{m}\right. \\
\left.\quad \times\left(1-c-\frac{1}{W-n}\right)^{n-m}\left(\frac{m+1-c-(1 /(W-n))}{m+1}\right)\right) \\
\left.\quad+\frac{W-n+1}{W-n}\left(1-c-\frac{1}{W-n+1}\right)^{n}-\left(1-c-\frac{1}{W-n}\right)^{n+1}\right]>0
\end{aligned}
$$

We cannot present an analytic solution because we have been unable to prove that $E U_{i}^{\text {Law }}\left(D C, C_{-i}\right)-E U_{i}^{\text {Law }}\left(C, C_{-i}\right)$ is increasing in $n$. However, we report computational results to demonstrate the workings of the model. Table 1, in the Appendix, reports $n^{*}$ (the maximum sized network that sustains cooperation) and $\operatorname{Pr}$ (the probability of third-party contract enforcement being used), given values for $\delta^{*}, b$, and $c$. We report the results allowing $\delta^{*}$ to equal $0.75,0.85$, and 0.95 and $b$ to equal $0.0001,0.0002$, and 0.0003 . The parameter $c$ is evaluated in intervals of 0.02 on the unit interval. The 

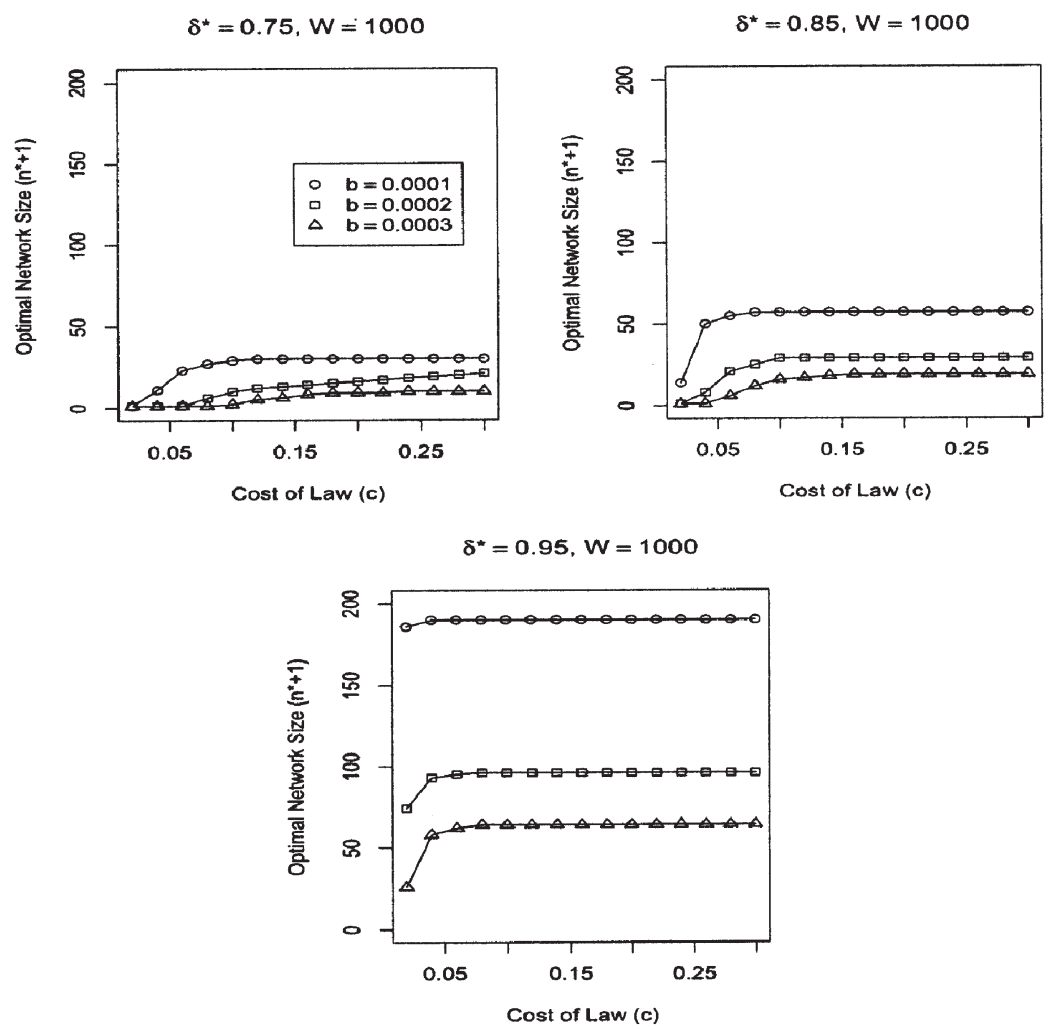

Figure 2. Optimal Number of Network Members $\left(n^{*}+1\right)$ as a Function of $c, b$, and $\delta^{*}$

network sizes are, of course, bounded above by the size of sustainable networks when there is no possibility of third-party contract enforcement. We set $W=1000$.

The comparative static results for the parameters $b$ and $\delta$ from the case with no law continue to hold when legal enforcement becomes possible. All else equal, the optimum network size is weakly increasing in $\delta$ and weakly decreasing in $b$. These relationships are shown in Figure 2.

The most important results concern the relationship between the cost of law and the sustainability of informal networks. The cost of law (c) affects the optimum network size. As $c$ decreases - that is, as legal contracts become less expensive to use - the optimum number of partners decreases. However, for most values of $c, n^{*}$ is positive. Thus, informal networks and legal contract enforcement can coexist even when every player has the option to use either method. 
Although the option of legal contract enforcement can reduce the size of informal networks, law only begins to have an effect on optimal group size when it is sufficiently inexpensive. Furthermore, when $c$ is sufficiently low, $n^{*}$ can change very quickly.

For example, consider the case we examined earlier: $b=0.0001$ and $\delta^{*}=0.85$. For all values of $c \geq 0.08$, each player prefers to have $n^{*}=56$ partners. In other words, players have as many partners when the law guarantees them a minimum per-turn payoff of approximately 0.92 as they do when law is not an option at all. When $c$ drops to 0.06 - so that a payoff of 0.94 is guaranteed $-n^{*}$ shrinks to 54 , still not much of a change. But as soon as $c$ drops to 0.02 - guaranteeing a payoff of $0.98-n^{*}$ drops to 13 . The large decrease in $c$ from 1 to 0.08 does not change $n^{*}$ at all. But the much smaller decrease in $c$ from 0.08 to 0.02 reduces $n^{*}$ by almost 60 per cent.

This suggests that the observation made by some researchers that in many societies law has little or no effect on informal trade networks does not imply that law is inherently irrelevant in those societies for cultural or ideological reasons. Until law becomes sufficiently inexpensive, it is expected to be used only infrequently and to have little effect on the size of informal networks. However, once the cost of law is sufficiently low, small changes in the cost of law can have a dramatic impact on informal networks.

The point at which lowering $c$ begins to have an effect on $n^{*}$ depends on the values of the other parameters. $n^{*}$ begins to decrease at higher values of $c$ when $\delta$ is lower and/or when $b$ is higher. That is, when the benefits of defection increase - whether because the immediate payoff from defection has gone up or the relative value of future trades has gone down - law will have an effect on optimal group size at higher values of $c$. This suggests several potentially observable implications. In a society with multiple sectors in which informal networks exist, if discount rates or benefits from defection differ across those sectors, we expect to see their informal networks beginning to erode at different times, as law becomes less expensive. Similarly, societies with differing levels of $b$ and $\delta$ will experience the effects of legal institutions at different levels of $c$.

In addition to the size of the informal networks, it is important to know the extent to which governmental contract enforcement will be used. This is easily determined in the model and is illustrated in Figure 3. An individual will rely on the formal legal system if and only if no partner in her informal network has a trading value that exceeds $((W-n / W-n+1)-c)$. Thus, the probability of making a third-party enforceable contract rather than trading within an informal network is $((W-n / W-n+1)-c)^{n^{*}}$.

This probability is decreasing in $c$ and in $n^{*}$. Since $n^{*}$ is itself a nondecreasing function of $c$, both $c$ 's direct effect on the probability of using the formal economy and its indirect effect through $n^{*}$ cut in the same direction. As we would expect, when law becomes less expensive the formal economy 

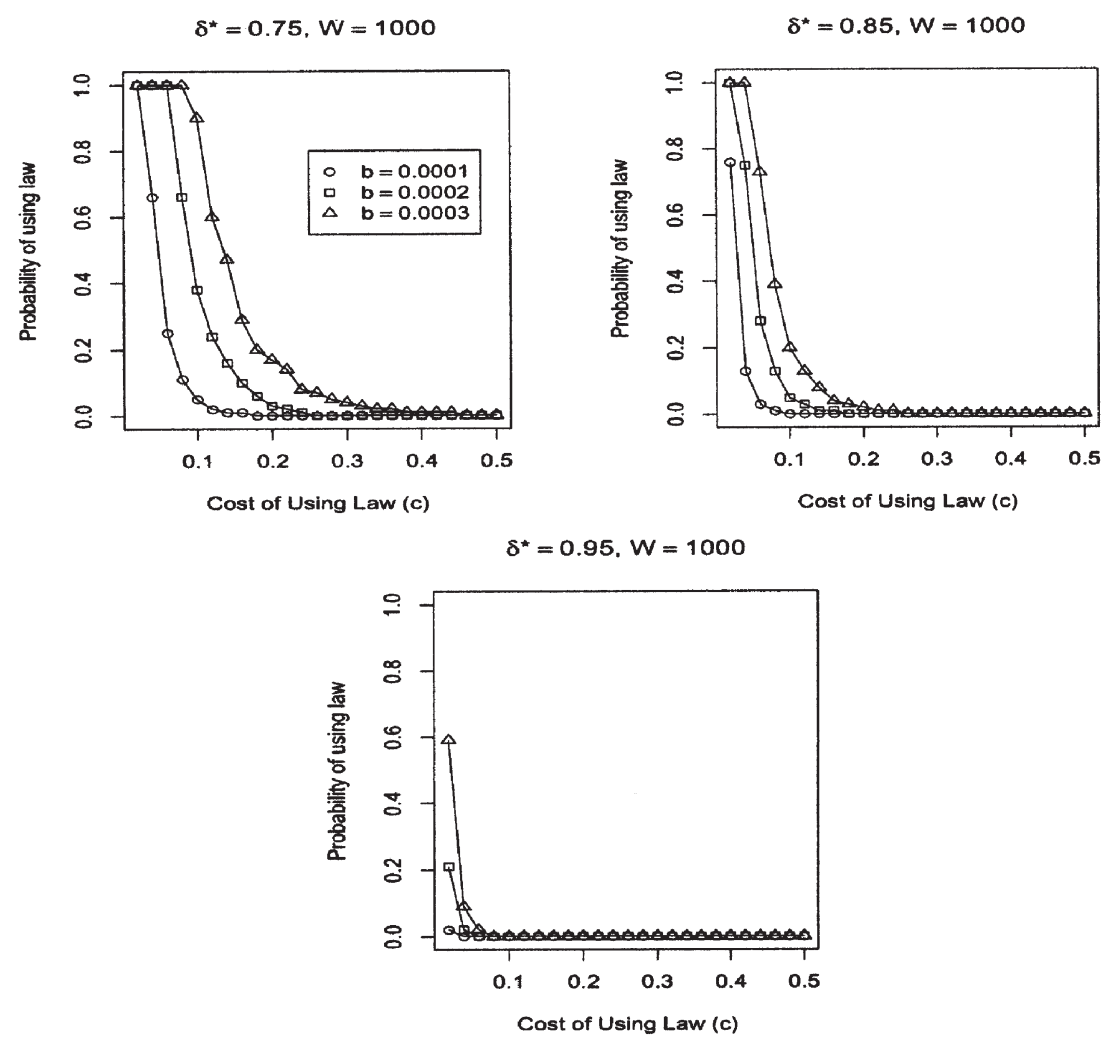

Figure 3. Probability of Writing a Formal Contract as a Function of $c, b$, and $\delta^{*}$

is used more frequently. Perhaps less intuitively, the probability of relying on formal contracts increases at an accelerating rate as $c$ decreases. This is due primarily to $c$ 's effect on $n^{*}$.

Individuals become much more likely to use the law as it becomes less costly, not so much because of the increasing affordability of legal contracts per se, but rather because inexpensive law reduces the size of informal networks, making trade within the informal economy relatively less desirable.

Consider the example from above. Although the probability of an individual using a legal contract is decreasing in $c$, this probability remains below 0.01 until $c$ falls somewhere below 0.08 . When $c=0.08$ the probability is $((1000-56 / 1001-56)-0.08)^{56} \approx 0.01$, when $c=0.06$ the probability increases to $((1000-54 / 1001-54)-0.06)^{54} \approx 0.03$, and when $c=0.02$ the probability is $((1000-13 / 1001-13)-0.02)^{13} \approx 0.76$. This example highlights the possibility of coexistence of formal and informal economies. In this latter case, 76 per cent of economic interactions make use of third-party 
contract enforcement. Nonetheless, individuals remain members of relatively large informal networks.

The size of $c$ 's direct effect on the probability of using the formal economy (as opposed to its indirect effect through $n^{*}$ ) is dependent on the values of the other parameters. In the preceding example, $c$ 's primary effect on the probability of trading in the formal economy was through its effect on $n^{*}$, because $n^{*}$ was relatively large when $c$ was close to 1 .

Thus, the exponential impact of $n^{*}$ swamped the effect of a change in $c$ (that is, any value between 0 and 0.92 raised to the $56^{\text {nd }}$ power translates to a probability very close to 0 ). However, the direct effect of $c$ is more pronounced in cases where $n^{*}$ is relatively small even when $c$ is close to 1 .

Another interesting question, within the context of this model, is what the optimal cost of the law is from the perspective of economic agents. When law becomes inexpensive enough, then networks are completely eroded. At this point all actors trade out of network and so their expected utility is decreasing in the cost of law. Thus, trivially, the economic agents' expected utility is maximized when the cost of law is zero.

The more interesting question arises when one considers the case where it is not feasible for third-party contract enforcement to become so inexpensive that networks are entirely eroded. In this scenario, economic agents face a trade-off. On the one hand, as third-party contract enforcement becomes less expensive, the cost of trading out of network decreases, which is to the good. On the other hand, as third-party enforcement becomes less expensive, informal network size shrinks, which means that the agents are forced to trade out of network more often and therefore they bear the costs of writing a contract more often, which is to the bad. As can be seen in Figure 4, as a result of this trade-off, agents' utility is typically not monotonic in the cost of contract enforcement. That is, subject to the constraint that contract enforcement cannot become inexpensive enough to entirely erode informal networks, economic agents prefer for contract enforcement not to become too inexpensive because this forces them to write contracts more often than they otherwise would.

These results have implications for understanding the politics of developing legal systems. Government provision of legal contract enforcement does not necessarily eliminate informal networks. However, unless law becomes inexpensive enough to erode informal networks significantly, the legal system will be used very infrequently. Governments concerned with providing widely used legal enforcement services must recognize this trade-off. Furthermore, marginal changes in the efficiency of the legal system have a larger effect in economies with relatively small informal networks. In these situations, increases in the efficiency of the legal system may have a significant effect on the frequency with which formal contracts are used, even when the size of informal networks is unaffected. 

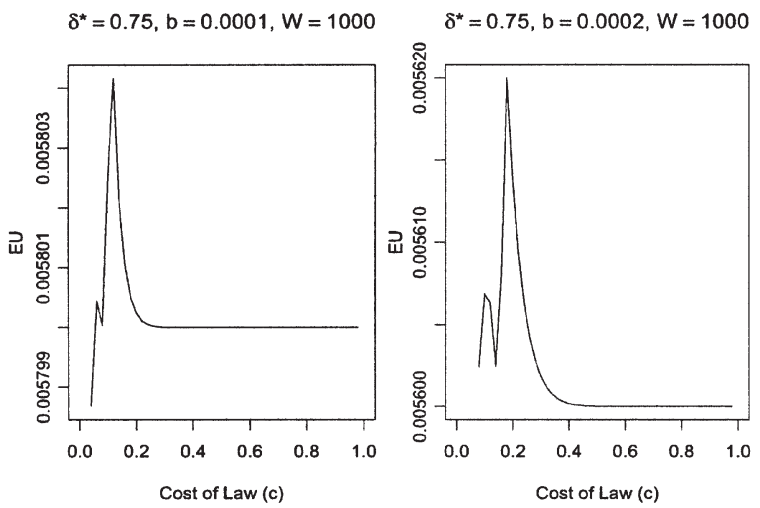

$\delta^{*}=0.75, b=0.0003, W=1000$

$\delta^{*}=0.85, b=0.0001, W=1000$
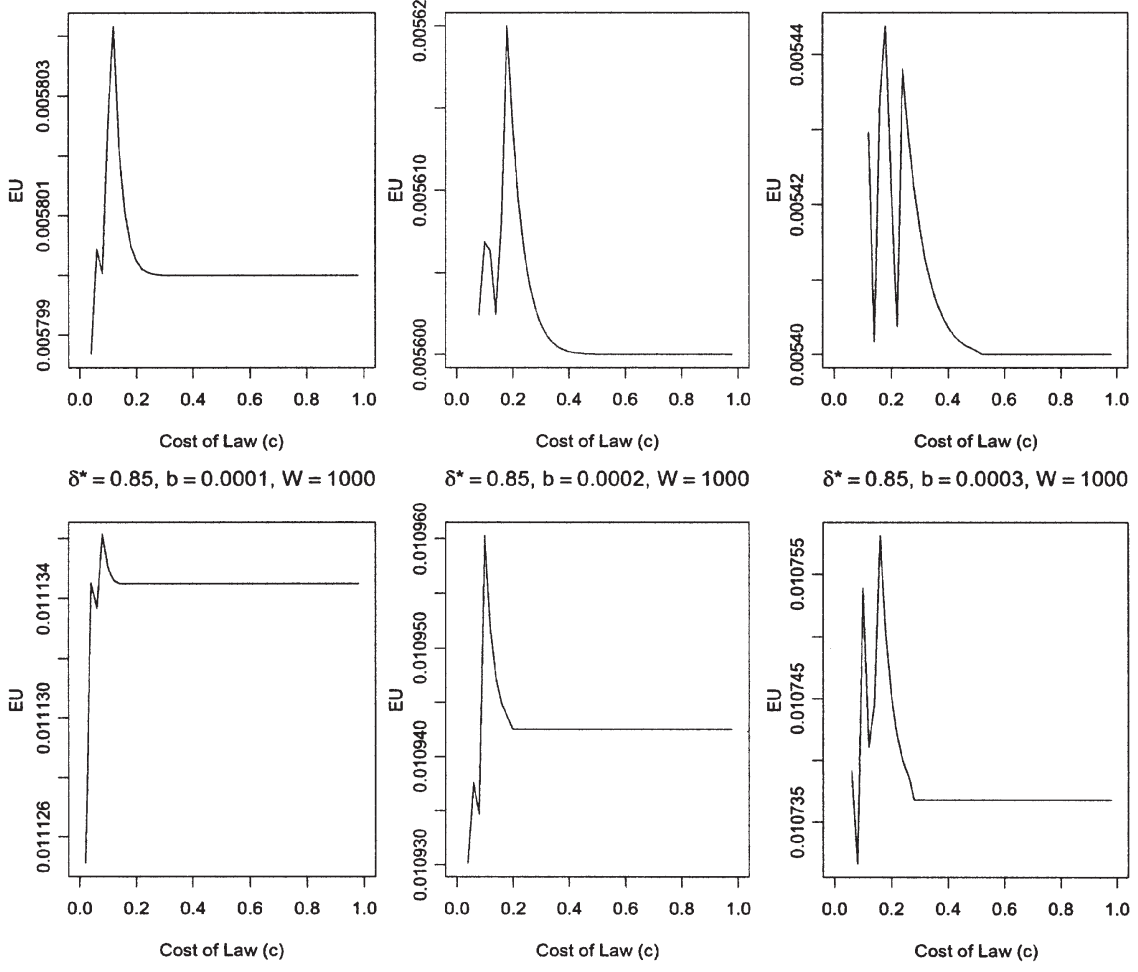

$\delta^{*}=0.85, b=0.0003, W=1000$
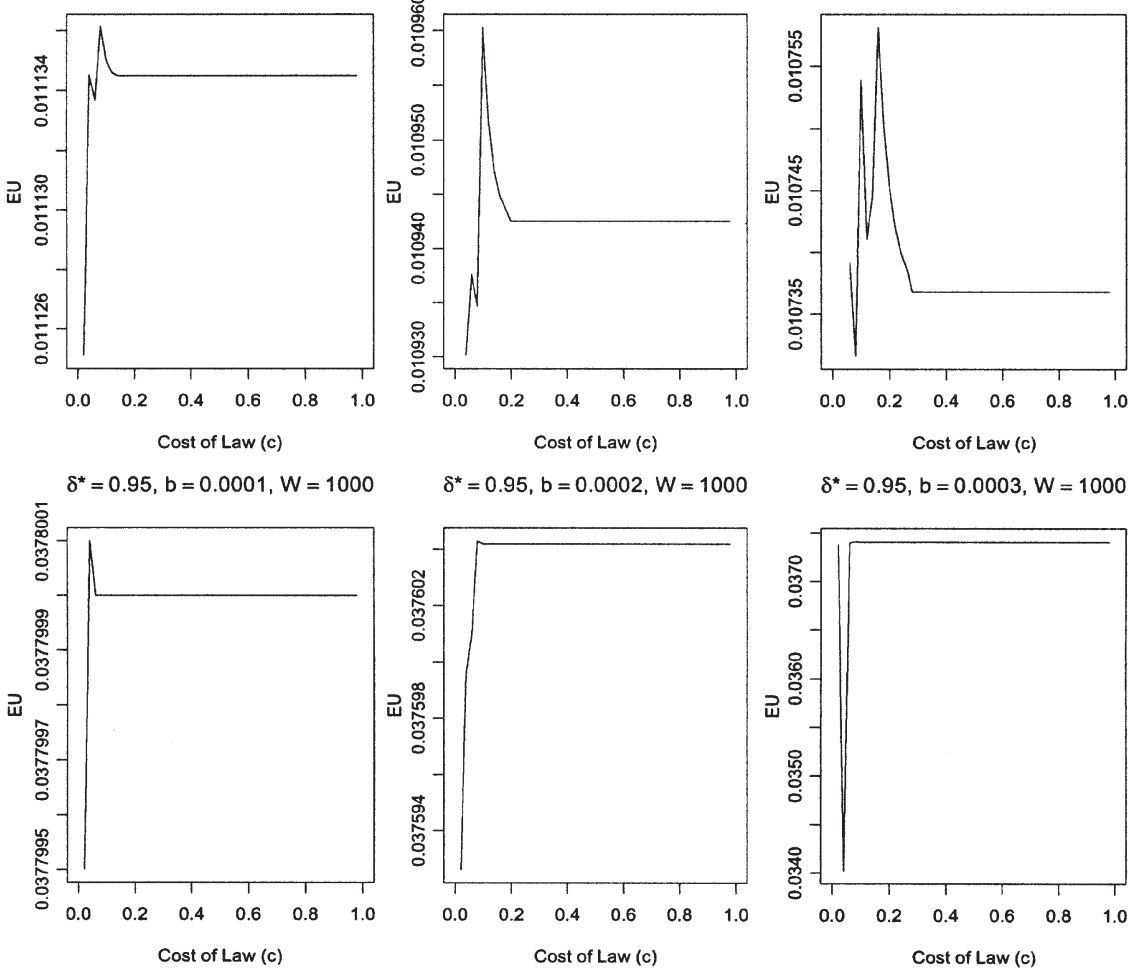

$\delta^{\star}=0.95, b=0.0002, W=1000$

$\delta^{*}=0.95, b=0.0003, W=1000$
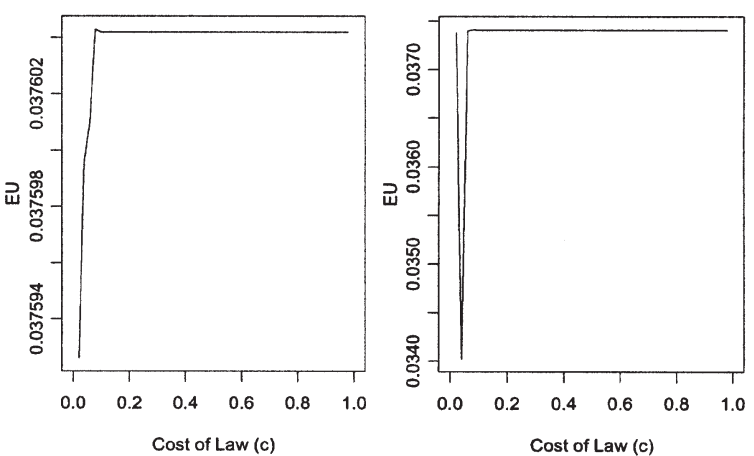

Figure 4. Expected Utility in Optimal Networks of Size Greater Than 0 as a Function of $c, b$, and $\delta^{*}$ 


\section{Conclusion}

Economic life is embedded in complex social structures. Among the most important of these are informal trade networks, where economic activity is sustained not through formal legal channels but through relationships of trust. An important question for students of the relationship between government policy, social structure, and economic activity is how the introduction of third-party contract enforcement interacts with and affects self-sustaining informal networks.

To address this question, we developed a model of informal trade networks and the effects of formal legal institutions on such networks. Building on the logic of punishment-based enforcement, we established that a tradeoff exists between the profitability of trade in an informal network, which increases as the size of the network increases, and the sustainability of cooperation, which becomes more difficult as network size increases. Because of this trade-off, the size of an informal trade network in which cooperation can be sustained is bounded above. We further explored the effects of changing discount rates and benefits from defection on the equilibrium size of informal networks. The size of cooperative networks increases when members value the future more and decreases when the benefit from defection increases.

Extending the model to include the possibility of legally enforceable contracts, our computational analysis suggested six results. First, in most cases, our model, consistent with empirical observations, predicts that informal and formal economies will co-exist. Moreover, individuals are not segregated into either the informal or formal economy, but operate in both. Second, the existence of third-party contract enforcement decreases the optimal size of informal trade networks, sometimes by a large amount. Third, the existence of legally enforceable contracts has little effect on the size of informal networks until such contracts become sufficiently inexpensive. Once contracting costs fall below a certain threshold, though, small changes in the price of using law can have dramatic effects on the size of informal networks. This result is consistent with the empirical observation that, in many cases, formal contracts are infrequently used, but it contradicts the assertion that this lack of use implies the social or cultural irrelevance of law. Instead, it suggests that little-used legal institutions may not be sufficiently inexpensive. Fourth, the threshold below which less expensive law begins to have an effect on informal networks increases as the benefits of defection increase and/or the weight given to the future decreases. Fifth, increases in the efficiency of law increase the frequency with which legal contracts are used, in part because of the greater affordability of such contracts, but primarily because inexpensive law erodes informal networks, making contractual exchange relatively 
more attractive. Sixth, for this reason, economic agents may not always prefer for the cost of contract enforcement to decrease.

These results notwithstanding, it is clear that our model omits much that is of interest to students of informal networks including trust, information sharing, ethnic or cultural ties, and norms of reciprocity. Earlier we argued that omitting these factors simply made the task of demonstrating network sustainability more difficult. However, we also want to argue that there is a relationship between our model and the role of more sociological factors such as trust or cultural norms in sustaining networks. In particular, the central idea in our model is that there is a trade-off between size and sustainability. Size offers economic benefits but also makes it more difficult to sustain good behavior. We focused on a particular mechanism for sustaining cooperation: punishment. However, trust, norms, and cultural ties are all likely to exhibit similar dynamics. The larger the group, the less powerful are the ties that bind people together. Trust is likely to develop more strongly in small groups. As such, trust-based mechanisms, just like punishmentbased mechanisms, put a limit on how large a sustainable network can grow. Thus, while we have not modeled the evolution of trust in groups, it is not surprising that our results are similar to Uzzi's (1996, 1997, 1999) empirical findings regarding the optimal size of networks in his studies of trust-based networks. Punishment and trust may ultimately prove to be closely linked concepts within the context of informal networks.

\section{Appendix}

\section{Expected Utility of Cooperation with Law}

There are four scenarios to consider:

\section{(a) Player $\boldsymbol{i}$ is the selector and chooses a trading partner in her network}

Player $i$ is the selector with probability $\alpha$. He or she chooses a trading partner in his or her network only if there is at least one member who is more valuable than the value of trading in the larger society. The expected value of trading in the larger society is the largest draw from $W-n-1$ draws from a uniform distribution on $[0,1]$ minus the costs of contract enforcement. This has expected value $(W-n-1 / W-n)-c$. The probability that any individual in $i$ 's network is more valuable than this is $1-(W-n-1 /(W-n))-c=c+(1 / W-n)$. The probability, then, that $m \leq n$ members of $i$ 's network are more valuable than trading in the larger society has probability given by the binomial: $\left(\begin{array}{c}n \\ m\end{array}\right)\left(c+(1 /(W-n))^{m}(1-c-(1 / W-n))^{n-m}\right.$. Finally, if $m$ members of $i$ 's network are more valuable than using third-party contract enforcement, then the expected utility of the trade is given by the $m^{\text {th }}$ order statistic of $m$ draws from a uniform distribution on $[1-c-(1 / W-n), 1]$. We can calculate this using the fact that the pdf of the $k^{\text {th }}$ order statistic from $n$ draws of a distribution 
$f(x)$ is given by $f_{k}(x)=[n ! /(k-1) !(n-k) !] f(x) F(x)^{k-1}(1-F(x))^{n-k}$ (Arnold et al., 1992). Thus, the pdf of the $n^{\text {th }}$ order statistic from $n$ draws is $f(x)=F(x)^{n-1} f(x) n$. Further, the pdf of the uniform distribution on $[a, b]$ is $1 /(b-a)$ and the cdf is $(x-a) /(b-a)$. Thus, the pdf of the $n^{\text {th }}$ order statistic of $n$ draws from a uniform on $[a, b]$ is $f_{n}(x)=\left[(x-a)^{n-1} n /(b-a)^{n}\right]$. The expected value of the $n^{\text {th }}$ order statistic is then given by:

$$
\int_{a}^{b} x \frac{(x-a)^{n-1} n}{(b-a)^{n}} d x=\frac{n}{(b-a)^{n}} \int_{a}^{b} x(x-a)^{n-1} d x .
$$

Integrating by parts shows that this expected value can be rewritten:

$$
\frac{n}{(b-a)^{n}}\left(\left.\frac{x(x-a)^{n}}{n}\right|_{a} ^{b}-\int_{a}^{b} \frac{(x-a)^{n}}{n} d x\right)=\frac{n b+a}{n+1} .
$$

Plugging in the relevant values for $a$ and $b$ we find that the expected value of a trade in network, when $m$ members of the network are more valuable than trading outside of the network is given by:

$$
\frac{m+1-c-\frac{1}{W-n}}{m+1}
$$

Thus, the overall expected utility in this scenario is

$$
\alpha \sum_{m=1}^{n}\left(\begin{array}{c}
n \\
m
\end{array}\right)\left(c+\frac{1}{W-n}\right)^{m}\left(1-c-\frac{1}{W-n}\right)^{n-m}\left(\frac{m+1-c-\frac{1}{W-n}}{m+1}\right)
$$

\section{(b) Player $i$ is the selector and trades out of network}

Again the probability that $i$ is the selector is $\alpha$. He or she trades out of network only if all members of their network are less valuable than $1-(1 /(W-n))-c$ which occurs with probability $(1-(1 /(W-n))-c)^{n}$. If this does occur, the expected value of the trade is simply the highest draw from $W-n-1$ draws minus the cost of enforcement, which has expected value $1-(1 / W-n)-c$. Thus, the expected utility in this scenario is:

$$
\alpha\left(1-c-\frac{1}{W-n}\right)^{n+1}
$$

(c) Someone else in player $i$ 's network is chosen as the selector, chooses to trade within the network, and chooses to trade with $i$

Deriving this payoff follows the exact same logic as in point (a) and it is given by:

$$
\alpha \sum_{m=1}^{n}\left(\begin{array}{c}
n \\
m
\end{array}\right)\left(c+\frac{1}{W-n}\right)^{m}\left(1-c-\frac{1}{W-n}\right)^{n-m}\left(\frac{m+1-c-\frac{1}{W-n}}{m+1}\right)
$$


(d) Someone not in player $i$ 's network is the selector, chooses to trade out of network, and chooses $i$

Deriving this payoff follows the same logic as in point (b) and it is given by:

$$
\alpha\left(1-c-\frac{1}{W-n}\right)^{n+1}
$$

Thus, the expected utility of the cooperative strategy is:

$$
\begin{aligned}
E U_{i}^{L a w}\left(C, C_{-i}\right)= & R+\frac{2 \alpha \delta}{1-\delta}\left[\left(1-c-\frac{1}{W-n}\right)^{n+1}\right. \\
& +\sum_{m=1}^{n}\left(\begin{array}{c}
n \\
m
\end{array}\right)\left(c+\frac{1}{W-n}\right)^{m}\left(1-c-\frac{1}{W-n}\right)^{n-m} \\
& \left.\times\left(\frac{m+1-c-\frac{1}{W-n}}{m+1}\right)\right]
\end{aligned}
$$

Expected Utility of Defection with Law

A similar procedure yields the expected utility from defecting, except that after defecting player $i$ now has a group of size $n$ rather than $n+1$. However, he or she assumes that others still have a group of size $n$ because of the assumption that all others cooperate. Player $i$ defects in round one, securing an expected payoff of $R+b$ in that round. Then his or her expected utility is the summation of five terms.

(e) Player $\boldsymbol{i}$ is the selector and chooses a trading partner in her network

The procedure for deriving the expected utility is the same as in (a) above and yields:

$$
\begin{gathered}
\alpha \sum_{m=1}^{n-1}\left(\begin{array}{c}
n-1 \\
m
\end{array}\right)\left(c+\frac{1}{W-n+1}\right)^{m}\left(1-c-\frac{1}{W-n+1}\right)^{n-1-m} \\
\quad \times\left(\frac{m+1-c-\frac{1}{W-n+1}}{m+1}\right)
\end{gathered}
$$

(f) Player $\boldsymbol{i}$ is the selector and trades outside his or her network The procedure is the same as in (b) above and yields:

$$
\alpha\left(1-c-\frac{1}{W-n+1}\right)^{n}
$$


(g) Someone else in player $i$ 's network is the selector, trades within network, and selects to trade wth $i$

The procedure is the same as in (c) earlier and yields:

$$
\frac{\alpha(n-1)}{n} \sum_{m=1}^{n}\left(\begin{array}{c}
n \\
m
\end{array}\right)\left(c+\frac{1}{W-n}\right)^{m}\left(1-c-\frac{1}{W-n}\right)^{n-m}\left(\frac{m+1-c-\frac{1}{W-n}}{m+1}\right)
$$

(h) Someone (other than the player against whom $i$ has already defected) not in $i$ 's network is the selector, trades out of network, and selects $i$

The procedure is the same as above and yields:

$$
\alpha\left(1-c-\frac{1}{W-n}\right)^{n+1}
$$

(i) The player against whom $i$ defected is the selector, trades out of network, and selects $i$ The procedure is the same as above and yields:

$$
\frac{\alpha}{W-n}\left(1-c-\frac{1}{W-n+1}\right)^{n}
$$

Thus, player $i$ 's expected utility from defecting once, given that all others cooperate, is:

$$
\begin{aligned}
E U_{i}^{\text {Law }}\left(D C, C_{-i}\right)= & R+b+\frac{\alpha \delta}{1-d}\left[\sum_{m=1}^{n-1}\left(\begin{array}{c}
n-1 \\
m
\end{array}\right)\left(c+\frac{1}{W-n+1}\right)^{m}\right. \\
& \times\left(1-c-\frac{1}{W-n+1}\right)^{n-1-m}\left(\frac{m+1-c-(1 /(W-n+1))}{m+1}\right) \\
& +\sum_{m=1}^{n}\left(\begin{array}{c}
n \\
m
\end{array}\right)\left(c+\frac{1}{W-n}\right)^{m}\left(1-c-\frac{1}{W-n}\right)^{n-m} \\
& \times\left(\frac{m+1-c-(1 /(W-n))}{m+1}\right)+\frac{W-n+1}{W-n} \\
& \left.\times\left(1-c-\frac{1}{W-n+1}\right)^{n}+\left(1-c-\frac{1}{W-n}\right)^{n+1}\right]
\end{aligned}
$$


=

*

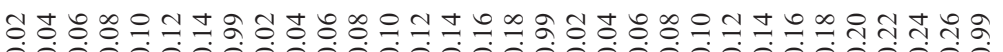

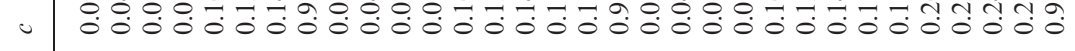

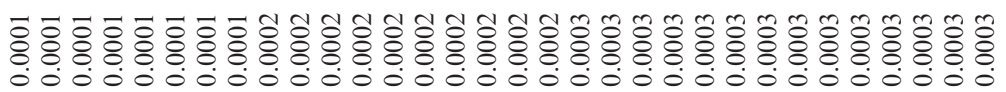

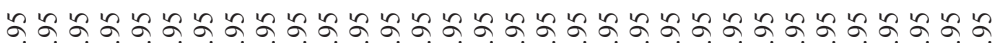

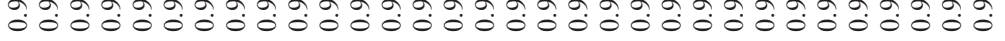
=

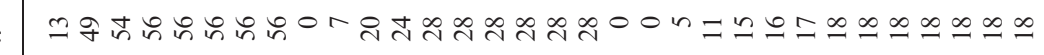

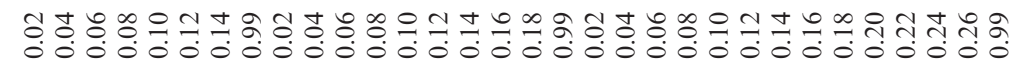

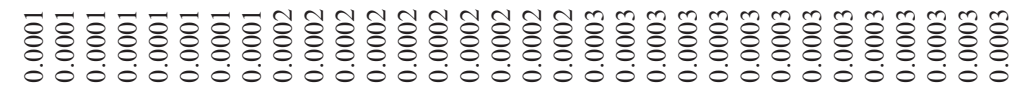

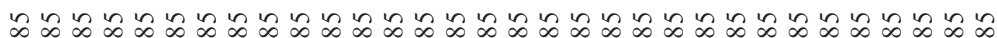

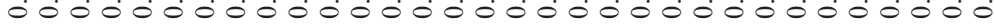

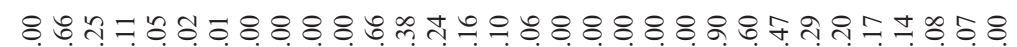

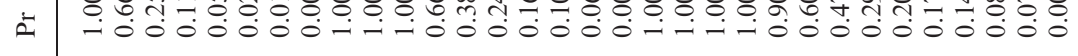

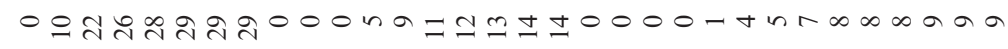

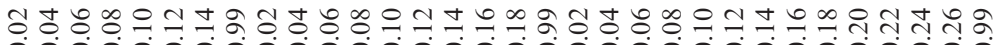
00000000000000000000000000000000

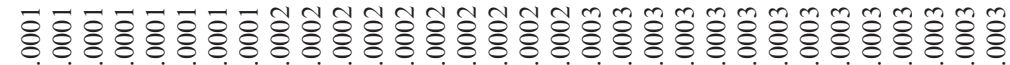
$\infty$

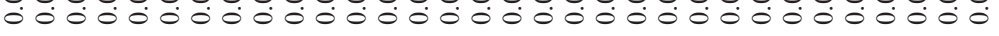




\section{REFERENCES}

Arnold, Barry C., N. Balakrishnan and H.N. Nagaraja (1992) A First Course in Order Statistics. New York: John Wiley and Sons.

Benson, Bruce L. (1990) The Enterprise of Law: Justice Without the State. San Francisco: Pacific Research Institute for Public Policy.

Bernstein, Lisa (1992) 'Opting Out of the Legal System: Extralegal Contractual Relations in the Diamond Industry', Journal of Legal Studies 12(1): 115-57.

Colson, Elizabeth (1974) Tradition and Contract. Chicago: Aldine.

Cooter, Robert D. (1996) 'Decentralized Law for a Complex Economy: The Structural Approach to Adjudicating the New Law Merchant', University of Pennsylvania Law Review 144(5): 1643-96.

Cooter, Robert D. and Janet T. Landa (1984) 'Personal Versus Impersonal Trade: The Size of Trading Groups and Contract Law', International Review of Law and Economics 4(1): 15-22.

De Soto, Hernando (1989) The Other Path: The Invisible Revolution in the Third World. New York: Harper and Row.

DiMaggio, Paul and Hugh Louch (1998) 'Socially Embedded Consumer Transactions: For What Kinds of Purchases Do People Most Often Use Networks?', American Sociological Review 63(5): 619-37.

Edelman, Lauren B. and Mark C. Suchman (1997) 'The Legal Environments of Organizations', Annual Review of Sociology 23: 479-515.

Ellickson, Robert C. (1991) Order Without Law: How Neighbors Settle Disputes. Cambridge, MA: Harvard University Press.

Fafchamps, Marcel (1996) 'The Enforcement of Commercial Contracts in Ghana', World Development 24(3): 427-48.

Fearon, James D. and David D. Laitin (1996) 'Explaining Interethnic Cooperation', American Political Science Review 90(4): 715-35.

Granovetter, Mark (1973) 'The Strength of Weak Ties', American Journal of Sociology 78: 136080.

Granovetter, Mark (1985) 'Economic Action and Social Structure: The Problem of Embeddedness', American Journal of Sociology 91: 481-510.

Greif, Avner (1993) 'Contract Enforceability and Economic Institutions in Early Trade: The Maghribi Traders' Coalition', American Economic Review 83(3): 525-48.

Kali, Raja (1999) 'Endogenous Business Networks', Journal of Law, Economics and Organization 15(3): 615-36.

Kranton, Rachel E. and Anand V. Swamy (1999) 'The Hazards of Piecemeal Reform: British Civil Courts and the Credit Market in Colonial India', Journal of Development Economics 58: $1-24$.

Landa, Janet T. (1981) 'A Theory of the Ethnically Homogenous Middleman Group: An Institutional Alternative to Contract Law', Journal of Legal Studies 10(2): 349-62.

Lee, Tahirih V. (1993) 'Risky Business: Courts, Culture, and the Marketplace', University of Miami Law Review 47: 1335-414.

Lomborg, Bjorn (1996) 'Nucleus and Shield: The Evolution of Social Structure in the Iterated Prisoner's Dilemma', American Sociological Review 61(April): 278-307.

Macaulay, Stewart (1963) 'Non-contractual Relations in Business: A Preliminary Study', American Sociological Review 28: 55-67.

Macy, Michael W. and John Skvoretz (1998) 'The Evolution of Trust and Cooperation Between Strangers: A Computational Model', American Sociological Review 63(5): 638-60.

Milgrom, Paul R., Douglass C. North, and Barry R. Weingast (1990) 'The Role of Institutions in the Revival of Trade: The Law Merchants, Private Judges, and The Champagne Fairs', Economics and Politics 2(1): 1-23. 
Mizruchi, Mark S. and Linda Brewster Stearns (2001) 'Getting Deals Done: The Use of Social Networks in Bank Decision-Making', American Sociological Review 66(5): 647-71.

Moore, Sally Falk (1978) 'Law and Social Change: The Semi-Autonomous Social Field as an Appropriate Subject of Study', in S.F. Moore (ed.) Law as Process: An Anthropological Approach, pp. 54-81. London: Routledge \& Kegan Paul.

North, Douglass C. (1990) Institutions, Institutional Change, and Economic Performance. Cambridge: Cambridge University Press.

Platteau, Jean-Philippe (1994) 'Behind the Market Stage Where Real Societies Exist - Part I: The Role of Public and Private Order Institutions', Journal of Development Studies 30(3): 533-77.

Polanyi, Karl (1957) The Great Transformation. Boston: Beacon Press.

Portes, Alejandro and Saskia Sassen-Koob (1987) 'Making It Underground: Comparative Material on the Informal Sector in Western Market Economies', American Journal of Sociology 93(1): 30-61.

Posner, Eric A. (1996) 'Law, Economics, and Inefficient Norms', University of Pennsylvania Law Review 144(5): 1697-744.

Powell, Walter W. and Laurel Smith-Doerr (1994) 'Networks and Economic Life', in Neil J. Smelser and Richard Swedberg (eds) Handbook of Economic Sociology. Princeton, NJ: Princeton University Press and Russell Sage Foundation.

Shapiro, Susan P. (1987) 'The Social Control of Impersonal Trust', American Journal of Sociology 93(3: 623-58).

Skocpol, Theda (1985) 'Bringing the State Back in: Strategies of Analysis in Current Research', in Peter B. Evans, Dietrich Rueschemeyer, and Theda Skocpol (eds) Bringing the State Back In, pp. 3-37. Cambridge: Cambridge University Press.

Uzzi, Brian (1996) 'The Sources and Consequences of Embeddedness for the Economic Performance of Organizations: The Network Effect', American Sociological Review 61(4): 674-98.

Uzzi, Brian (1997) 'Social Structure and Competition in Interfirm Networks: The Paradox of Embeddedness', Administrative Science Quarterly 42(1): 35-67.

Uzzi, Brian (1999) 'Embeddedness in the Making of Financial Capital: How Social Relations and Networks Benefit Firms Seeking Financing', American Sociological Review 64(4): 481505 .

Uzzi, Brian and Ryon Lancaster (2004) 'Embeddedness and Price Formation in the Corporate Law Market', American Sociological Review 69(3): 319-44.

Weiss, Linda (1987) 'Explaining the Underground Economy: State and Social Structure', The British Journal of Sociology 38(2): 216-34.

Winn, Jane Kaufman (1994) 'Relational Practices and the Marginalization of Law: Informal Financial Practices of Small Businesses in Taiwan', Law and Society Review 28(2): 193-232.

ETHAN BUENO DE MESQUITA is an assistant professor in the Department of Political Science and resident fellow at the Center in Political Economy at Washington University. His research focuses on applications of game theory to terrorism and political violence, legislative and electoral institutions, and law and politics. His work has appeared in the American Journal of Political Science, American Political Science Review, International Organization, Journal of Politics and elsewhere. ADDRESS: Department of Political Science, CB1063, Washington University, 1 Brookings Drive, St. Louis, MO 63130, USA [email: ebuenode@artsci.wustl.edu]. 
MATTHEW STEPHENSON is an assistant professor at Harvard Law School. His research focuses on formal models of law and development, judicial politics, and administrative law. His work has appeared in the American Political Science Reviewe, Harvard Law Review, Journal of Law, Economics and Organization, Journal of Legal Studies and elsewhere. ADDRESS: Harvard Law School, Harvard University, Cambridge, MA 02138, USA [email: mstephen@law.harvard.edu]. 